\title{
Harmonic Measurement and Analysis during Electric Vehicle Charging ${ }^{*}$
}

\author{
Mohd Zamri Che Wanik¹, Mohd FadzilMohd Siam', Afida Ayob ${ }^{2}$, Subiyanto², Azah Mohamed², \\ Abu HanifahAzit ${ }^{3}$, SaharuddinSulaiman ${ }^{3}$, Mohamed Azrin Mohamed $\mathrm{Ali}^{4}$, \\ Zahrul Faizi Hussein ${ }^{1}$, Ahmad Kamil MatHussin ${ }^{1}$ \\ ${ }^{1}$ TNB Research Malaysia, Malaysia \\ ${ }^{2}$ Power System Research Group, UniversitiKebangsaan Malaysia, Malaysia \\ ${ }^{3}$ TNB Distribution Malaysia, Malaysia \\ ${ }^{4}$ Malaysian Green Technology Corporation, Bandar BaruBangi, Malaysia \\ Email: mzamri@tnbr.com.my
}

Received 2013

\begin{abstract}
This paper presentsand describes harmonic measurement and analysis of studying harmonic propagation during electric vehicle (EV) charging. The measurement study is performed on a golf cart and two modern type of EVs. Harmonics from a single EV charging and a group of EV charging was measured. The voltage and current waveform during the charging was captured and analyzed to investigate the harmonic components that exist in the electrical system. Total current harmonic distortion (THDi) and total voltage harmonic distortion (THDi) were both calculated. Modern electric vehiclesare found to release low THDi but higher THDv compared to a golf cart. On the measurement study during charging of a group of EV, it is found that the summation of THD is not linear with a number of vehicles. The finding of the study reveals that harmonic contamination from EV charging on electrical grid is not as critical as thought by most of power system researchers and engineers.
\end{abstract}

Keywords: Electric Vehicle; Total Harmonic Distortion; Electric Vehicle Charging; Harmonic; Power Quality

\section{Introduction}

In light of high energy usage, environmental pollution and rising fossil fuel prices, current dependence on internal combustion engine (ICE) technology employed in vehicles should be reduced and the widespread use ofelectricvehicle (EV) as the transportation of choice in 20 to 30 years time should be increased. It is estimated that $\mathrm{EV}$ vehicle penetration will increase gradually where $35 \%$ is projected at 2020 and will reach $50 \%$ by the year of 2024 [1-2].

The general effect on distribution systems caused by the spread of EV will be substantial load increase and large increment of system voltage and harmonic distortion. Another issue that should be considered is the coincidence between the charging start time and the eventual evening load peak period, which varies with customer and country.

For charging, EVbatteries need DC current so the grid AC current will be converted to DC by battery charger. The charger is basically the rectifier/inverter with con-

\footnotetext{
*TNB is an abbreviation for TenagaNasionalBerhad which is a main electrical utility company in Malaysia. TNB research is a research arm of TNB.
}

troller integrated with protection circuit. This is where the concern rises because inverter/rectifier is known asa harmonic source. So one of the concerns with electric vehicle charging is the harmonic contamination to the electrical grid.

There is no agreement however on how much the total harmonic distortion (THD) can be released to the network during charging. In one of the published report, total current harmonic distortion (THDi) is reported between $2.36 \%$ to $5.26 \%$ at the beginning of charging and reaching up to $28 \%$ at the end of charging. However total voltage harmonic distortion (THDv) is claimed only to range between 1 and $2 \%$ with power factor close to unity. For commercial chargers, THDi from measurement recording values are between $60 \%$ to $70 \%$ [1,3-4].

The concern of the engineers and researchers are when a large number of EVs charging simultaneously to the power system grid. What is the sum of THD when EV multiplies in numbers?Many believethat THD will increase with the number of vehicles. It is however difficult to find a report that discusses this issue. Moreover the values indicate in the previous paragraph was reported [3-4] more than 10 years ago so the valuesdo not 
represent the actual amount ofharmonic generated from state-of-the-art charger technologies that is used in modern electric vehicles.

The study reported in this paper tries to investigate the harmonic distortion from a single EV and a group of EVs. The measurement was performed on an older type of $\mathrm{EV}$ and two modern types of EV. The results of the study is useful in understanding the harmonic distortion contribution from EV connected to the grid for charging.

This paper is organized as follow. First EV technology is briefly reviewed.The harmonic distortion limit then highlighted. Harmonic measurement during a single vehicle charging is then presented. Finally the harmonic distortion during charging of a group of $\mathrm{EV}$ is discussed and commented.

\section{Electric Vehicle Technology}

Electric vehicle that will be seen creating issues on the power system gridwill be of two types. First type is plug in hybrid where there is a combination of ICE and battery. The second type will be all electric vehicle where this vehicle depends solely on battery. For both types of EV, electrical power is needed from the grid for charging.

Example of typical PHEV hardware arrangement is depicted in Figure 1. This is for parallel type of PHEV. There is also series type of PHEV but the focus of this paper is on the grid connection issue so it is not important if the EV is of parallel or series type. For all electric vehicle, the components in the light green dash lines are not needed and removed leaving only batteries, charger, power electronic drive and propulsion electric motor.

When EV is charging, the only active components are charger and battery because EV is not moving. For grid interfacing studies, the EV can be represented electrically as depicted in Figure 2. Battery charger is basically a rectifier which converts AC current from the grid to DC current to charge the battery. The rectifier is normally of active type where the power electronic devices are employed for switching devices. In this diagram power electronic devices are IGBT.

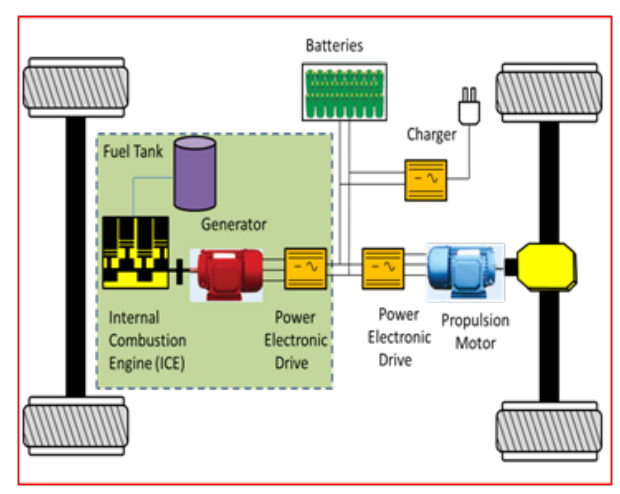

Figure 1. PHEV typical layout [5].

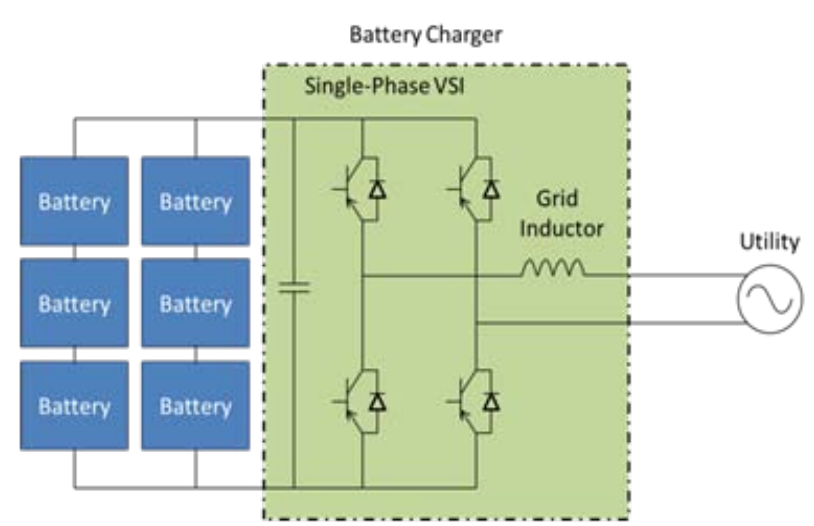

Figure 2. Battery charger circuit diagram [6].

EV charger is normally of conductive type eventhough inductive type is available. Conductive chargers have direct plug-in connection to the supply e.g. using an extension power cord to plug form the wall outlet into the $\mathrm{EV}$. Inductive charger on the other hand use magnetic coupling as a mode of energy transfer. Comparing these two types, conductive charger is simpler to design, having higher efficiency and more popular.

\section{Harmonics Distortion Limit}

Harmonicsdistortion has detrimental effects on electrical equipment inside power system.Severity of harmonic is determined by the percentage of total harmonic voltage distortion. Harmonic voltage is referred to as a sinusoidal voltage having frequency equal to an integer multiple of the fundamental frequency of $50 / 60 \mathrm{~Hz}$ supply. Total harmonic distortion is calculated as follows[7]:

$$
\begin{aligned}
T H D_{u} & =\sqrt{\frac{\sum_{h=2}^{40}\left(U_{h}\right)^{2}}{U_{1}}} \\
T H D_{i} & =\sqrt{\frac{\sum_{h=2}^{40}\left(I_{h}\right)^{2}}{I_{1}}}
\end{aligned}
$$

In Malaysia,the main utility company, TenagaNasional Berhad, has set a limit on total harmonic voltage distortion according to voltage level as tabulated in Table 1. For current there is no distortion limit set.

\section{Harmonic Measurement}

A few field measurement activities were conducted investigatethe harmonic during EV charging. The measurement is performed using Fluke power quality meter. The picture of the meter is portrayed in Figure 3. The meter has the capability to directly display the voltage and current waveforms in real time. In addition, the measurement 
data can be saved into the memory of the meter for further analysis.

For individual harmonic, three types of electric vehicle is compared. The first type of EV is a commercial type of modern EV ( EV1). Second type is modern EV prototype (EV 2). Third type is a golf cart. Due to classified and sensitive issues, the name of the manufacturers and the brand of these EVs are not disclosed.

Table 1. THDv limit in TNB Distribution system [7].

\begin{tabular}{cc}
\hline Voltage Level & THDv \\
\hline $33 \mathrm{kV}$ & $3 \%$ \\
$11 \mathrm{kV}$ & $4 \%$ \\
$0.4 \mathrm{kV}$ and below & $5 \%$ \\
\hline
\end{tabular}

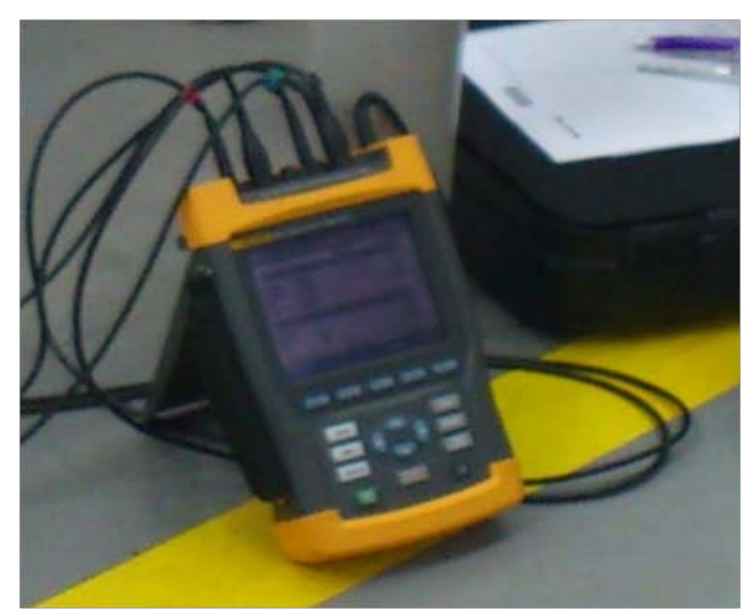

Figure 3. Fluke power quality meter.

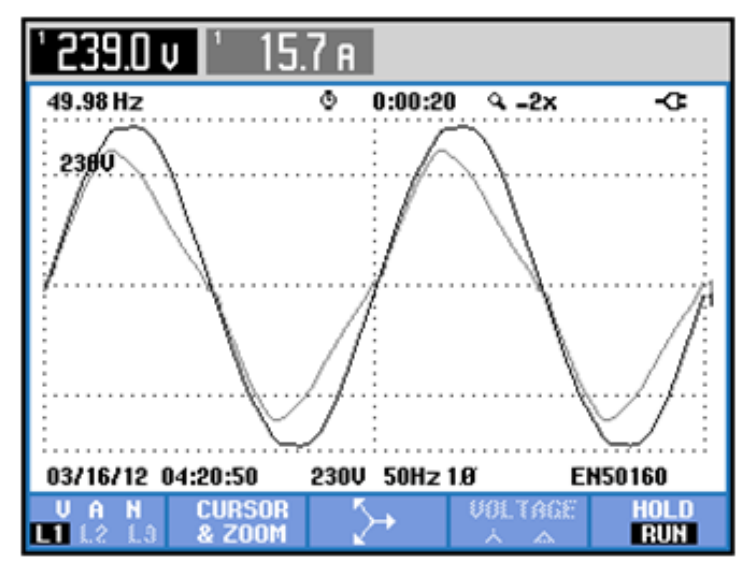

Figure 4. Modern EV 1 voltage and current waveform.

Figure 4 shows the voltage and current waveforms of EV 1. Figure 5 and 6 show THDv and THDi for EV 1 respectively. THDv and THDi after analysis are 1.5\% and $11.6 \%$ respectively. For EV 2, the voltage and current waveform are depicted in Figure 7. THDv and THDi for EV 2 is 1.2\% (Figure 8) and 9.2\% (Figure 9) respectively. Figure 10 shows the voltage and current waveform for the golf cart. Figure 11 and 12 shows THDv and THDi for the golf cart which are $1.1 \%$ and $34.4 \%$ respectively.

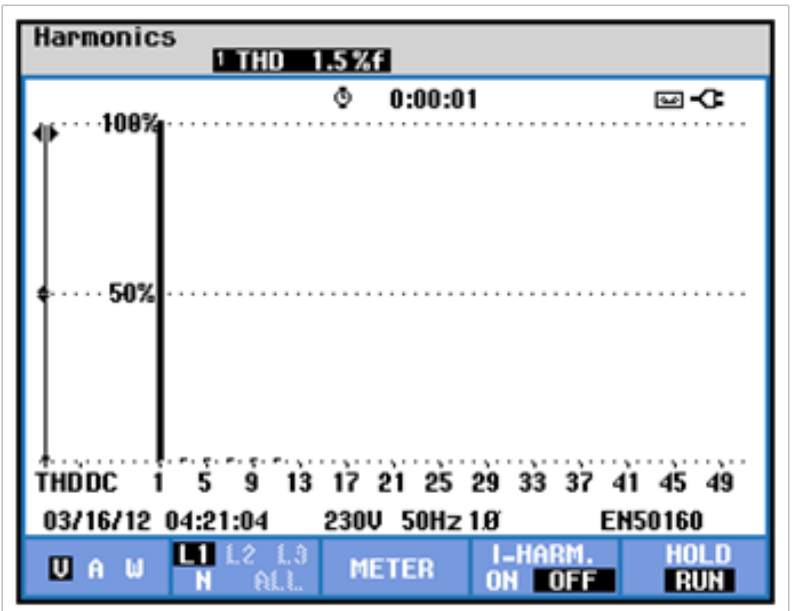

Figure 5. Total voltage harmonic distortion from EV 1.

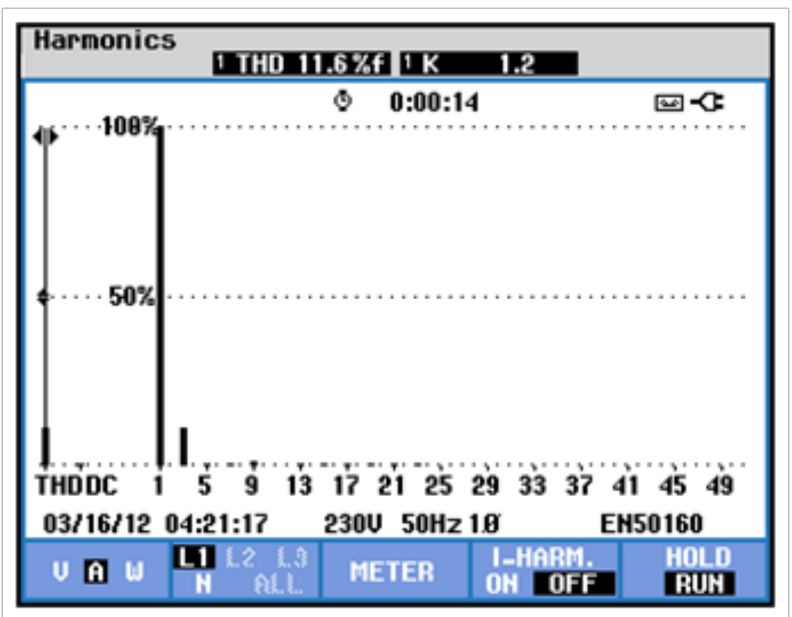

Figure 6. Total current harmonic distortion from EV 1.

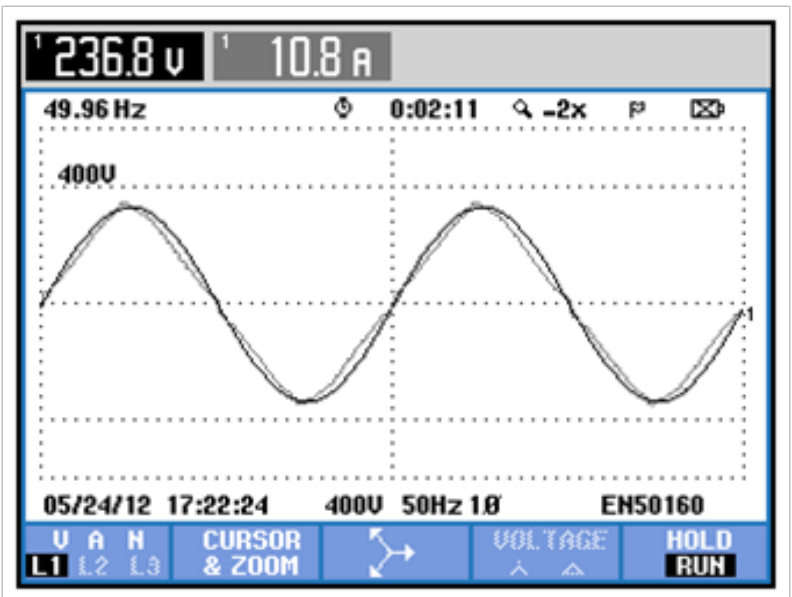


Figure 7. Modern EV 2 voltage and current waveform.

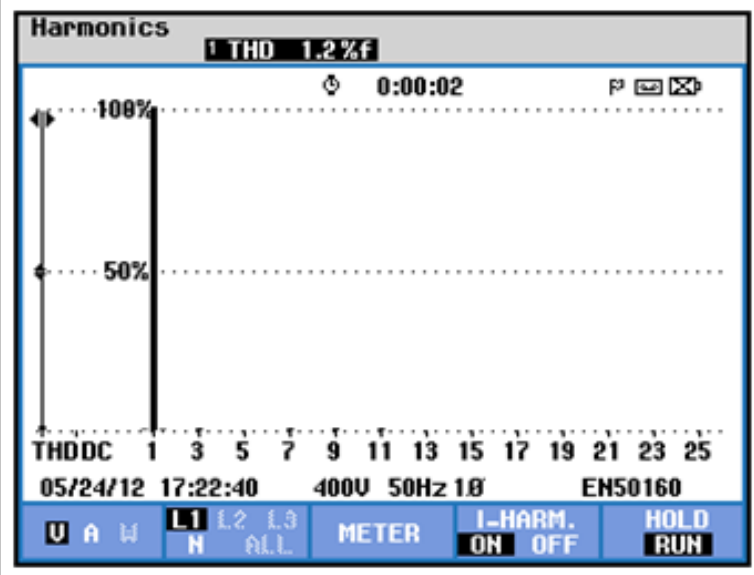

Figure 8. Modern EV 2 total voltage harmonic distortion.

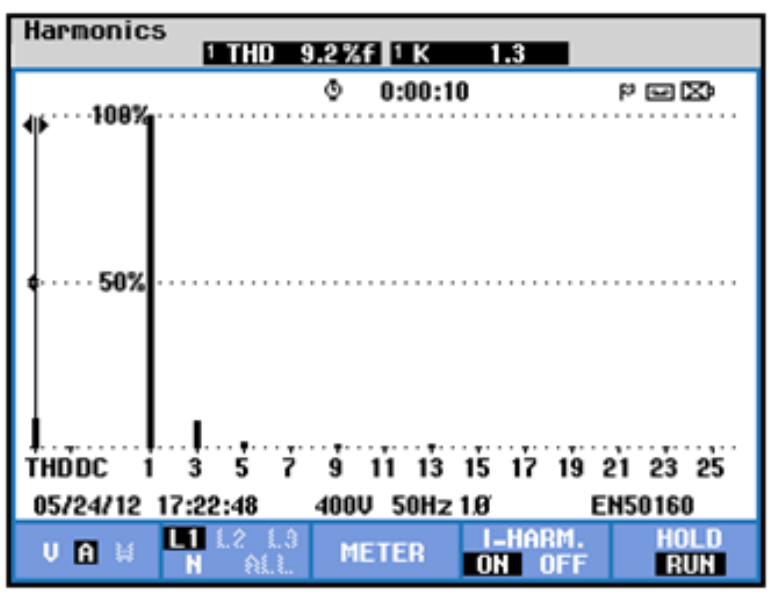

Figure 9. Modern EV 2 total voltage harmonic distortion.

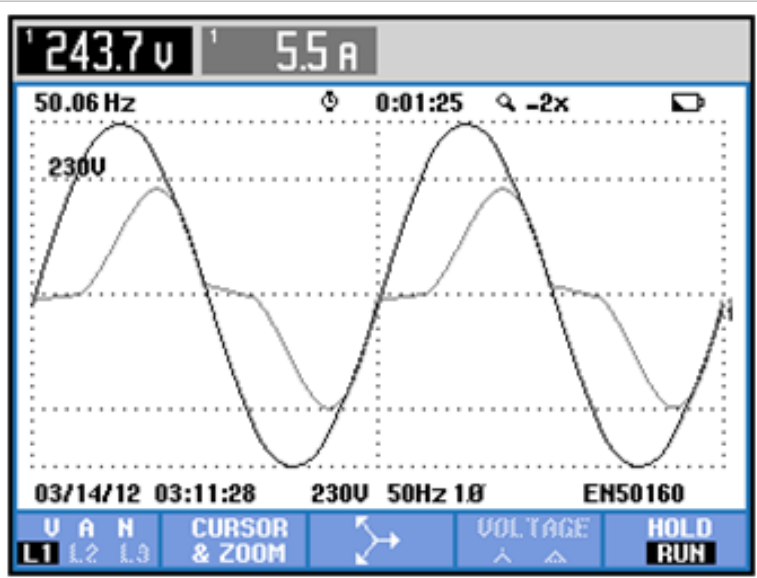

Figure 10. Golf cart voltage and current waveform.

The measurement results reveal that the THDi from chargers is low for modern EV but for THDv, modern $\mathrm{EV}$ is releasing higher distortion. The lower THDv from golf cart can be explained due to lower current magnitude drawn during the charging. For modern EV, even though THDi is lower, THDv is higher than measured for golf cart. This is due to higher current magnitude drawn by modern EV.

\section{Harmonic From a Group of EV}

In the previous section, THDv measured from a single EV was presented. The value was recorded lower than limit set by utility. But the concern on harmonic is when a group of EVs connected to the grid simultaneously for charging. There are many engineers who thought that the summation of THD from a group of EVs is linear with the sum of EV.To find out the answer, a measurement is performed to measure THD from a group of EVs.

In Malaysia, modern EV is not yet commercialized so the study cannot be performed on the commercial EVs. But there are many golf carts available which can be used in the study. The results will not represent the modern EV harmonic but the main objective is to investigate the sum of THD from a single EV and a group of [EV].

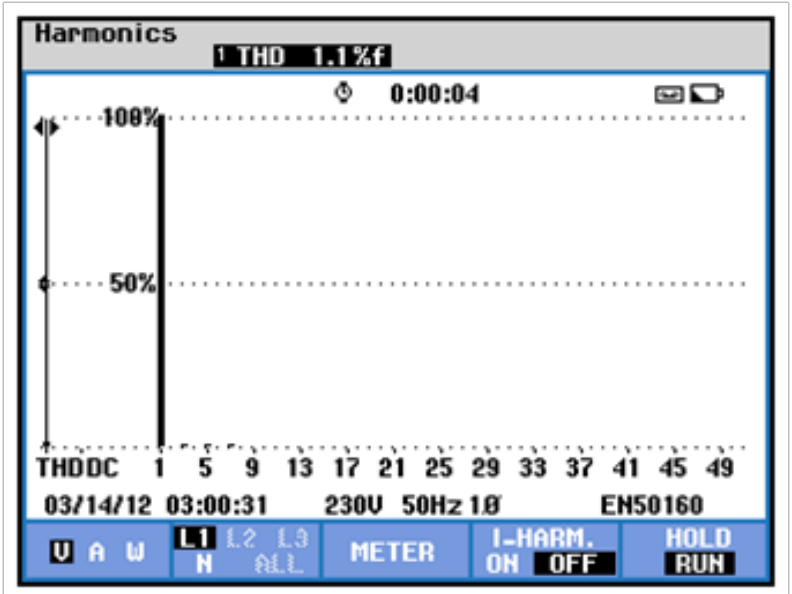

Figure 11. Golf cart total voltage harmonic distortion.

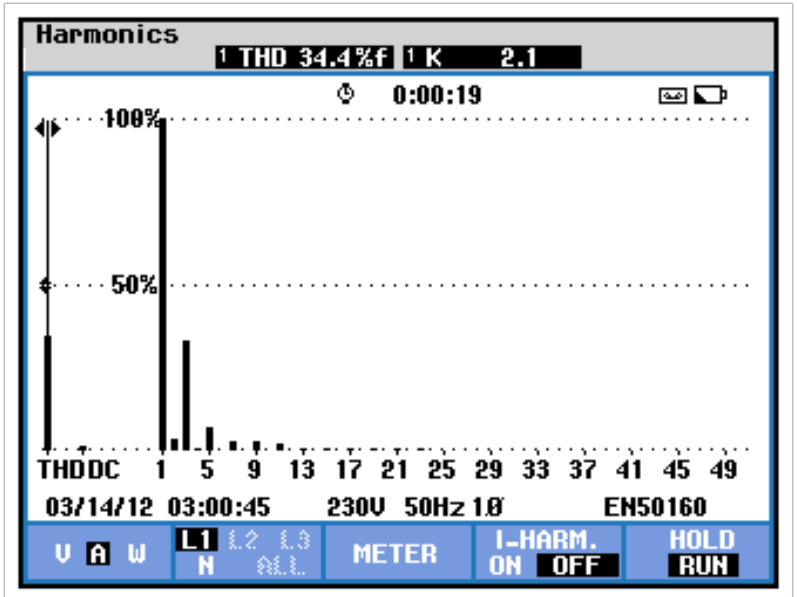


Figure 12. Golf cart total current harmonic distortion.

The measurement was performed at a golf club at Universiti Kebangsaan Malaysia. The measurement was carried out on a working day. On that day, it was raining from early morning until 10:00 am. But the golfing activities were active where all golf carts left the charging point by $9.00 \mathrm{am}$. The first golf cart returned to charging station after $11 \mathrm{am}$. The time, number of vehicle, and the line where they are connected are detailed in Table 2. The measured quantities are voltage and current harmonics distortion. The measurement data was recorded initially every one hour interval until 6:00 pm. Starting at 7:00 pm, the golf cart start to arrive more often so the measurement was taken for every 15 minutes.

The data are visualized through a graph as shown in Figure 14 for THDv and Figure 15 for THDi. Instead of time, the number of vehicles is used for $\mathrm{x}$-axis to facilitate the pattern of consumption from these EV. The line where these golf carts are connected were also identified. The consumption starts to increase substantially starting from 6:30 pm (18:30 hrs) when golfers start to return the golf cart to the pick-up point.

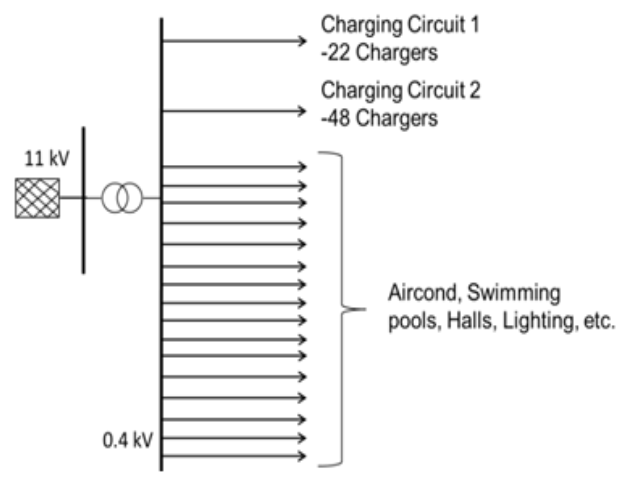

Figure 13. Golf Club distribution Circuit.

Table 2. Time, number of vehicle and connection.

\begin{tabular}{ccccc}
\hline \multirow{2}{*}{ Time } & \multirow{2}{*}{$\begin{array}{c}\text { Number of Ve- } \\
\text { hicle }\end{array}$} & \multicolumn{3}{c}{ Connection } \\
\cline { 3 - 5 } & 0 & L1 & L2 & L3 \\
\hline 11:00 & 1 & 1 & 0 & 0 \\
12:00 & 1 & 1 & 0 & 0 \\
13:00 & 1 & 1 & 0 & 0 \\
14:00 & 1 & 1 & 0 & 0 \\
15:00 & 2 & 2 & 0 & 0 \\
16:00 & 3 & 3 & 0 & 0 \\
17:00 & 0 & 0 & 0 & 0 \\
18:00 & 6 & 4 & 2 & 0 \\
18:30 & 12 & 4 & 4 & 4 \\
18:45 & 16 & 8 & 4 & 4 \\
19:00 & 18 & 8 & 6 & 4 \\
19:15 & 20 & 8 & 8 & 4 \\
19:30 & 22 & 8 & 8 & 6 \\
19:45 & & & &
\end{tabular}

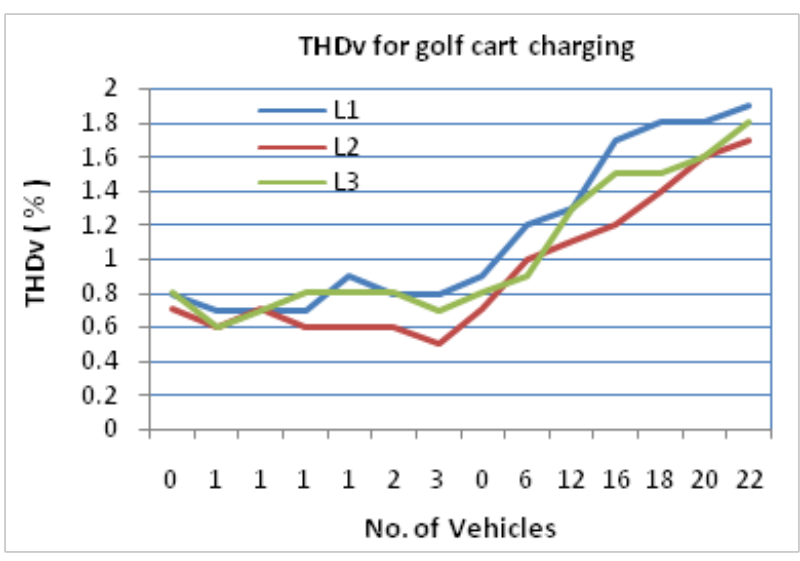

Figure 14. Measured THDv during monitoring.

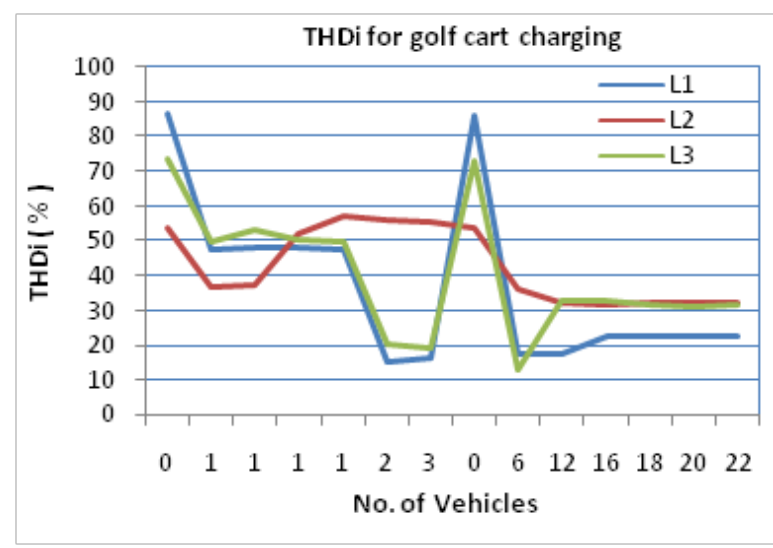

Figure 15. Measured THDi during charging.

The THD is also measured both for voltage and current as shown respectively in Figure 14 and Figure 15. Eventhough THDv for each single vehicle was measured $1.1 \%$ but a PCC, the value is only $0.7 \%$ for onevehicle. With the increaseof vehicles connected, the THDv steadily increase. For eight vehicles on L1, the recorded THDv is only $1.9 \%$.

For THDi of one vehicle, THDi 34.4\% is recorded but at PCC, THDi is recorded $47.8 \%$. With the increment of golf cart charging the THDi value at PCC decrease to $16.6 \%$ for 3 vehicles but increase again for12 vehicles. Surprisingly THDi do not increase much when vehicle increase from 16 to 22 on L1.

\section{Conclusion}

In this paper, the harmonic measurement study and analysis during electric vehicle charging is presented. The measurement is performed on golf carts and two modern types of EV. The measurement result shows that modern EV release lower THDi compared to a golf cart which is expected. Unfortunately for THDv, modern EV cause higher percentage of distortion. For a group of EV charging, THD for both voltage and current are found not 
to be the direct summation of the THD from a single vehicle. The results of the study areuseful in understanding the harmonic distortion contribution from EV connected to the grid for charging.

\section{Acknowledgements}

This investigation study is part of a project jointly carried out by TNB Research Malaysia, UniversitiKebangsaan Malaysia, TNB Distribution Malaysia and Malaysian Green Technology Corporation. The project is funded by TNB Research Malaysia through funding TNBR/RD55/ 2012 and partly supported by UniversitiKebangsaan Malaysia via research grant GGPM-2011-071.

\section{REFERENCES}

[1] R. Liu, L. Dow and E. Liu, “A survey of PEV Impact on Electric Utilities,"IEEE PES Innovative Smart Grid Technologies Conference, January, 17-19, 2011, Anaheim, CA, USA
[2] EPRI, "Environmental Assessment of Plug-In Hybrid Electric Vehicles,” Technical Report 1015325, July 2007.

[3] J. Orr, et al, "Current Harmonics, Voltage Distortion, and Powers Associated with Electric Vehicle Battery Chargers Distributed on the Residential Power System," IEEE Trans. On Industry Applications, Volume: IA-20, Issue 4,1984

[4] J. Gomez and M. Morcos, "Impact of EV Battery Chargers on the Power Quality of Distribution Systems," IEEE Power Engineering Review, October 2002.

[5] Emadi, A., “Transportation 2.0.,” IEEE Power and Energy, Vol. 9, No. 4, July/ Aug. 2011.

[6] W.Kramer, S. Chakraborty, B. Kroposki and H. Thomas, "Advanced power electronic interfaces for distributed energy systems - part 1: system and topologies," National Renewable Energy Laboratory, Golden, Colorado, Tech. Rep. NREL/TP-581-42672, Mar.2008.

[7] Malaysian Energy Commision, The Malaysian Distribution Code,

http://www.tnb.com.my/tnb/application/uploads/uploaded /the\%20malaysian\%20grid\%20code.pdf 